\title{
Profile and Treatment outcome of Laryngeal Cancer Patients attended at Orci from 2008 to 2011
}

\author{
*Muhoka Peter ${ }^{1}{ }^{2}$, Doreen Mathew ${ }^{1}$ and Alita Mrema ${ }^{2}$ \\ ${ }^{1}$ Department of Internal Medicine, Muhimbili National Hospital, Africa \\ ${ }^{2}$ Department of Radiation Oncology, Ocean Road Cancer Institute, Africa
}

Submission: May 19, 2017; Published: June 20, 2017

"Correspondence Address: Muhoka Peter, Department of Internal Medicine, Muhimbili National Hospital, Tanzania, East Africa, Tel: +255 713983 596; Email: muhokapeter80@gmail.com

\begin{abstract}
Laryngeal cancer is the cancer of the cells found in the larynx. The new cases diagnosed annually have significant geographical variation. Laryngeal cancer is more common to male compared female and more in low social economic class. It is more prevalent in elderly people and the glottis area is the most common site.

The high risk factors associated with laryngeal cancer include smoking cigarette, excessive alcohol consumption especially spirits, squamous cell carcinoma is by far the commonest histological type and the symptoms include hoarseness of voices, sore throat, painful swallowing and change in voice quality or enlarged neck nodes. In early stages, laryngeal cancer can be treated by surgery or radiotherapy and combination of radiotherapy and chemotherapy in late stages of the disease.

The aim of this hospital based cross sectional study was to describe the disease profile of the patient with laryngeal cancer attended at ocean road cancer institute, Tanzania from 2008to 2011. 72 patients were included in a study, $86.1 \%$ were males and $13.9 \%$ were females. The youngest patient was 35 years and the oldest patient had 84 years with mean age 58.1 years, where by $59.7 \%$ of the patients included in the study had primary education and below. $64.4 \%$ had history of both alcohol consumption and cigarette smoking prior to disease development and the glottis area was common disease site by $66.7 \%$ with squamous cell carcinoma the most histological type by $98.6 \%$.Majority had advanced disease stage III and IV with $73.6 \%$ of all patients included in the study where by the combination of chemotherapy and radiation treatment was common a treatment modality.
\end{abstract}

Keywords: Larynx; Laryngeal cancer; Glottis; Squamous cell carcinoma; Chemotherapy; Radiotherapy

Abbreviations: CRT: Chemo Radiation Therapy; HNC: Head and Neck Cancer; HPV: Human Papilloma Virus; IARC: International Agency for Research on Cancer; MUHAS: Muhimbili University of Health and Allied sciences; ORCI: Ocean Road Cancer Institute

\section{Introduction}

Laryngeal cancer is uncommon head and neck malignancy which develops inside the tissue of the larynx [1]. It is 18th most common cancer in the world representing approximately $2 \%$ of new cases diagnosed annually with significant geographical variation in incidence [2]. According to United Kingdom cancer research center it was estimated that there were over 150,000 new cases of laryngeal cancer in 2008 worldwide [3]. Countries with the highest incidence of laryngeal cancer includes Hungary were the incidence is 181.9; Belgium 152.4 and USA were the incidence is 142.6 per 100,000 according to data obtained from IARC [4].

In Tanzania, figures from Global cancer statistic center of 2008 give the estimated incidence of 5.3 per 100,000 in men and 0.3 per 100,000 in women, with estimated age standardized mortality rates of 3.5 per 100,000 and 0.2 per 100,000 in men and women respectively [5]. Laryngeal cancer is more common in male compared to female with a ratio of almost 5:1 [6] and it is more prevalent in among lower socio-economic class in which it is diagnosed at more advanced stages and the frequency of the disease increased along with age in both sexes [7].

In most recent studies shows glottic tumors forms the majority and subglottic tumors comprising only a few per cent of all laryngeal malignancies while some earlier studies indicate supraglottic dominance $[8,9]$. Tumors arising from different regions of the larynx probably have different risk factors and show considerable difference in clinical behavior and prognosis 
$[8,10]$. Usually Supraglottic cancers present with sore throat, painful swallowing, referred ear pain, change in voice quality, or enlarged neck nodes. Early vocal cord cancers are usually detected because of hoarseness of voice. Cancers arising in the subglottic area commonly involve the vocal cords and symptoms usually relate to contiguous spread.

Squamous cell carcinoma is by far the most common histological type, comprising $95 \%$ of laryngeal cancers. Other rare type of cancer arises from the other types of cells within the larynx including adenocarcinoma. The exact reason why a cell becomes cancerous is unclear. It is thought that something damages or alters certain genes in the cell, which make these cells abnormal and multiply out of control. There are certain risk factors that increases the chances of laryngeal cancer development including: age - more common in older people over 60 years, smoking habit, excessive alcohol consumption, poor diet especially a diet lacking certain vitamins and minerals, long term exposure to certain chemicals, fumes or pollutant may irritate the larynx and Human Papilloma Virus (HPV) has been shown in some studies to be associated with cancer of the larynx

For smokers, the risk of the developing laryngeal cancer decreases after the cessation of smoking but remains elevated even years later when compared to that of nonsmokers. The risk of second tumor is enhanced in a patient who has had a single cancer and continues to smoke and drink alcoholic beverages and the likelihood of a cure for the initial cancer, by any modality, is highly diminished.

The treatment advised for each case depends on various factors such as the exact site of the primary tumor in the larynx, the stage of the cancer, the grade of the cancerous cells and the general health of the patient. Although most early lesions can be cured by either radiation therapy or surgery, radiation therapy may be reasonable to preserve the voice, leaving surgery for salvage. Locally advanced lesions, especially those with large clinically involved lymph nodes, are poorly controlled with surgery, radiation therapy, or combined modality treatment. Distant metastases are also common, even if the primary tumor is controlled.

Patients treated for laryngeal cancers are at the highest risk of recurrence in the first 2 to 3 years. Recurrences after 5 years are rare and usually represent new primary malignancies. Close, regular follow-up is crucial to maximize the chance for salvage. Careful clinical examination and repetition of any abnormal staging study are included in follow-up, along with attention to any treatment-related toxic effect or complication. The survival rates for laryngeal cancer depends on the stage that the condition is diagnosed. Around 1 in 4 people with stage four laryngeal cancer will live at least five years after diagnosis [7]. The prognostic factors for laryngeal cancers include increasing $\mathrm{T}$ stage and $\mathrm{N}$ stage. Other prognostic factors may include sex, age, performance status, and a variety of pathologic features of the tumor, including grade and depth of invasion [11].

\section{Methodology}

\section{Study Design}

This was a hospital based cross-sectional retrospective study.

\section{Study setting}

This study was conducted at Ocean Road Cancer Institute in Dar Es Salaam, Tanzania. Ocean Road Cancer institute is located along Indian Ocean in Dar Es Salaam, Tanzania. The facility is one of the oldest health facilities in Tanzania founded in 1895 by German colonial government. The Institute works in partnership with the Tanzania community so as to create and maintain an integrated, accessible and affordable cancer health care system with quality services to improve health and wellbeing. Ocean Road Cancer Institute offers numerous patients services including laboratory services, diagnostic imaging, chemotherapy, radiotherapy, palliative care services, cervical and breast cancer screening and HIV/AIDS care and treatment clinic. Also Ocean Road Cancer Institute offers programs for undergraduate and postgraduate student as well as other health care workers, further more ORCI runs research projects in various aspects of cancer. Laryngeal cancer patients brought to ORCI are treated either by radiotherapy and chemotherapy or combination and most of them are brought in advanced stages.

\section{Study participants}

a. Target population: All patients with diagnosis of laryngeal cancer in Tanzania.

b. Accessible population: All patients referred to ORCI for treatment with diagnosis of laryngeal cancer.

c. Study population: All patients with laryngeal cancer who fulfill the eligibility criteria.

\section{Eligibility criteria}

\section{a. Inclusion criteria}

The study included all patients referred to ORCI with diagnosis of laryngeal cancer from January 2008 to December 2011, and whose baseline characteristics were determined before beginning of the therapy and had at least 1 follow-up visit.

\section{b. Exclusion criteria}

The study excluded subjects whose records were not available.

\section{Sampling procedure}

All patients who attended ORCI between 1st January 2008 and 31st December 2011 with a diagnosis of laryngeal cancer were identified from the central hospital registry. Hospital case-notes were retrieved for each patient. Details pertinent to patient demographics, diagnosis, disease severity and laterality, treatment, and outcome, were recorded. 


\section{Sample size}

The sample size for laryngeal cancer was calculated using a single proportion formula

$\mathrm{n}=\mathrm{z}^{2} \mathrm{p}(100-\mathrm{P}) / \varepsilon^{2}$

Where: $\mathrm{n}=$ Minimum sample size designed,

$\mathrm{z}=$ the point on standard normal deviation corresponding to $95 \%$ Confidence Interval which is 1.96 , (Zx of 1.96 approximated to 2 ),

$\mathrm{p}=$ The proportion of laryngeal cancer patients seen at ORCI (5\%), $\varepsilon=$ Margin of error set at 5\%.

$\mathrm{n}=(2)^{2} \times 5 \times(100-5) /(5)^{2} \mathrm{n}=76$.

From the formula the minimum number of patients with laryngeal cancer to be recruited in the study was found to be 76 Study variables.

The outcome variables were:

i. Complete remission

ii. Persistent disease

iii. Relapse

iv. Death

\section{Data collection}

Research assistants under the supervision of the principal investigator use data extraction forms to retrieve data from patient's records stored in manual files and or files on computer. The data extraction forms were capture demographic characteristics, severity of disease, treatment modalities and outcome of treatment and other variables of interest.

\section{Data Management and Statistical Analysis}

\section{a. Data Management}

The data extraction forms were carefully reviewed for completeness and consistency. In case of missing or inconsistent data was checked the patient periodical records or medical registers while ensuring utmost confidentiality of patient records and identity.

\section{b. Statistical analysis}

The data analysis was done using the SPSS version 21 for windows.

\section{c. Quality control}

The data obtained was coded, edited and cleaned before any statistical analysis was carried out on the data. Additional internal documentations such as variable and value labels were added and any necessary additional variables were created through algebraic or logical expressions. Study research assistants were trained before the start of the study. Data capture sheet will be pre-tested to improve consistency. Data was double entered to control for errors.

d. Ethical Considerations: Ethical clearance to conduct the study was obtained from MUHAS Ethical Committee. In addition ORCI was asked to allow a researcher to access the medical sites and files of patients with laryngeal cancer between Jan 2008 and Dec 2011.

\section{Results}

Information required was obtained from hospital registry and patients files. After excluding the patients whose information didn't fulfill the selection criteria, only 72 patients were included in the study and data extraction and analysis was performed and the results of socio-demographic characteristics and disease profile are presented below (Table 1).

Table 1: Demographic characteristics of patients with Laryngeal cancer.

\begin{tabular}{|c|c|c|}
\hline Variable & Number $(\mathbf{N}=\mathbf{7 2})$ & \% \\
\hline Sex & & \\
\hline Male & 62 & 86.1 \\
\hline Female & 10 & 13.9 \\
\hline Age of the patient & & 0 \\
\hline$<30$ & 0 & 56.9 \\
\hline $31-60$ & 31 & 43.1 \\
\hline$>60$ & 1 & \\
\hline $\begin{array}{c}\text { Formal education } \\
\text { level }\end{array}$ & 42 & 1.4 \\
\hline Non & 22 & 58.3 \\
\hline Primary school & 7 & 30.6 \\
\hline $\begin{array}{c}\text { Secondary school } \\
\text { Post-secondary } \\
\text { school }\end{array}$ & & 9.7 \\
\hline
\end{tabular}

There were more male than female, with ratio of $6.2: 1$, with majority of the patients, $56.9 \%$ at the age of less than 60 years which is the most economic and active group with the mean age of 58.71 years. $58.3 \%$ of the patients had primary school education, $30.6 \%$ attend secondary school and only $9.7 \%$ had post-secondary school education (Table 2). Majority of Laryngeal cancer patient had history of both alcohol consumption and cigarette smoking $69.4 \%$ prior to disease progression, history of alcohol consumption alone was $18.1 \%$ and cigarette smoking alone were $12.5 \%$ among the laryngeal cancer patients presented at ORCI from 2008 to 2011 (Table 3). The common site for the laryngeal cancer among the patients attended at ORCI from 2008 to 2011 was glottis area with $66.7 \%$ followed by supraglottic area with $33.3 \%$. There was no any patient presented with disease at subglottic area (Table 4). 
Table 2: Associated factors for Laryngeal cancer among the patients with laryngeal cancer attended at ORCI from 2008 to 2011.

\begin{tabular}{|c|c|c|}
\hline Variable & Frequency & \% \\
\hline $\begin{array}{c}\text { Smoking cigarette } \\
\text { alone }\end{array}$ & 9 & 12.5 \\
\hline $\begin{array}{c}\text { Alcohol consumption } \\
\text { alone }\end{array}$ & 13 & 18.1 \\
\hline $\begin{array}{c}\text { Alcohol and cigarette } \\
\text { smoking }\end{array}$ & 50 & 69.4 \\
\hline Total & 72 & 100 \\
\hline
\end{tabular}

Table 3: The common site of the disease among the patients with laryngeal cancer attended at ORCl.

\begin{tabular}{|c|c|c|}
\hline $\begin{array}{c}\text { Variable Frequency } \\
\%\end{array}$ & & \\
\hline Supraglottis & 24 & 33.3 \\
\hline Glottis & 48 & 66.7 \\
\hline Sub glottis & 0 & 0 \\
\hline & 72 & 100 \\
\hline
\end{tabular}

Table 4: The common histological type.

\begin{tabular}{|c|c|c|}
\hline Variable & Frequency & \% \\
\hline $\begin{array}{c}\text { Squamous cell } \\
\text { carcinoma }\end{array}$ & 71 & 98.6 \\
\hline Adenocarcinoma & 1 & 1.4 \\
\hline & 72 & 100 \\
\hline
\end{tabular}

Table 5: The common presentation among the patients of laryngeal cancer attended at ORCI from 2008 to 2011.

\begin{tabular}{|c|c|}
\hline Variable & Frequency \\
\hline Hoarse voice & $67(93 \%)$ \\
\hline Sore throat & $17(23 \%)$ \\
\hline Lump in the neck & $13(18 \%)$ \\
\hline Trouble in swallowing & $34(47 \%)$ \\
\hline
\end{tabular}

The squamous cell carcinoma was found to be the common histological presentation $98.6 \%$ compared to adenocarcinoma which was in about $1.4 \%$ of all patients with laryngeal carcinoma attended at ORCI from 2008 to 2011 (Table 5). Majority of the patients attended at ORCI with laryngeal cancer from 2008 to 2011 had hoarse voice, 93\%. Trouble in swallowing had 47\%,

sore throat $23 \%$ and lump in the neck had least number of the patients $17 \%$ (Table 6). From the figure above, it shows that majority of the patients present at ORCI at stage three , $37.5 \%$ and stage four $36.1 \%$ which are late stages. Small proportion of the patients present with stages one and two, 9.7\% and $16.7 \%$ which are early stages (Table 7).

Table 6: Stage of the disease presented by laryngeal cancer patients attended at ORCI from 2008 to 2011.

\begin{tabular}{|c|c|c|}
\hline Variable & Frequency & $\mathbf{\%}$ \\
\hline Stage I & 7 & 9.7 \\
\hline Stage II & 12 & 16.7 \\
\hline Stage III & 27 & 37.5 \\
\hline Stage IV & 26 & 36.1 \\
\hline
\end{tabular}

Combination of chemotherapy and radiotherapy was the most common treatment modality, 88.9\% combination of surgery followed by chemotherapy and radiotherapy was $6.9 \%$, surgery followed by radiotherapy was $1.4 \%$ and radiotherapy alone was $2.8 \%$ (Table 8). Disease stage and treatment modality shows association with treatment outcome with $\mathrm{p}<0.0001$ and 0.014 respectively, but there were no any association between treatment outcome and sex, age or level of education of the patient (Table 9). Disease stage was highly associated with treatment outcome with $\mathrm{p}<0.001$, OR 18.342 with $95 \% \mathrm{CI}$ of 4.192- 80.244. But treatment modality was not associated directly to the treatment outcome.

Table 7: The treatment modalities provided to the patients with laryngeal cancer attended at ORCI from 2008 to 2011.

\begin{tabular}{|c|c|c|}
\hline Variable & Frequency & \% \\
\hline $\begin{array}{c}\text { Chemotherapy and } \\
\text { EBRT }\end{array}$ & 64 & 88.9 \\
\hline $\begin{array}{c}\text { Surgery followed by } \\
\text { chemotherapy and } \\
\text { EBRT }\end{array}$ & 5 & 6.9 \\
\hline $\begin{array}{c}\text { Surgery followed by } \\
\text { EBRT }\end{array}$ & 1 & 1.4 \\
\hline Radiotherapy alone & 72 & 2.8 \\
\hline Total & 2 & 100 \\
\hline
\end{tabular}

Table 8: The association between treatment outcome and the sociodermographic characteristics and disease profile of laryngeal cancer patients attended at ORCI from 2008 to 2011.

\begin{tabular}{|c|c|c|c|c|c|}
\hline Variables & \multicolumn{5}{|c|}{ Treatment outcome } \\
\hline & Complete remission & Persistent disease & Relapse & Death & p-value \\
\hline Sex & & & & 0 & 2 \\
\hline Male & 4 & 6 & 1 & 0 & 0.632 \\
\hline Female & 14 & 45 & & 0 & \\
\hline Patients age & 0 & 1 & 0 & 2 & \\
\hline$<30$ yrs & 11 & 31 & 1 & & 0.541 \\
\hline 31-60 yrs & 7 & 19 & & & \\
\hline Disease stage & & & & & \\
\hline
\end{tabular}


Cancer therapy \& Oncology International Journal

\begin{tabular}{|c|c|c|c|c|c|}
\hline I & 7 & 0 & 0 & 0 & \\
\hline II & 10 & 2 & 0 & 0 & \\
\hline III & 0 & 24 & 1 & 2 & \\
\hline IV & 0 & 26 & 0 & 0 & $<0.0001$ \\
\hline \multicolumn{6}{|l|}{ Education achieved } \\
\hline Illiterate & 0 & 1 & 0 & 0 & \\
\hline Primary & 12 & 28 & 1 & 1 & \\
\hline Secondary & 2 & 19 & 1 & 0 & \\
\hline Post-secondary & 4 & 3 & 0 & 0 & 0.481 \\
\hline \multicolumn{6}{|l|}{$\begin{array}{l}\text { Treatment } \\
\text { modalities }\end{array}$} \\
\hline Chemo + EBRT & 11 & 50 & 1 & 2 & \\
\hline Only EBRT & 1 & 1 & 0 & 0 & \\
\hline Surgery + EBRT & 1 & 0 & 0 & 0 & \\
\hline Surg + chemo + EBRT & 5 & 0 & 0 & 0 & 0.014 \\
\hline
\end{tabular}

Table 9: Logistic regression for outcome of treatment against disease stage and treatment modality to the laryngeal cancer patients attended at $\mathrm{ORCl}$ from 2008 to 2011.

\begin{tabular}{|c|c|c|c|}
\hline Variable & \multicolumn{3}{|c|}{ Treatment outcome } \\
\hline p-value OR & $95 \% \mathrm{CI}$ & 1.125 & $0.414-3.054$ \\
\hline Treatment modality & 0.817 & 18.342 & $4.192-80.244$ \\
\hline Disease stage & $<.001$ & & \\
\hline
\end{tabular}

\section{Discussion}

Laryngeal cancer is the second most common respiratory cancer after lung cancer and it is fourteenth in all malignancies. Despite the advance in investigation and treatment of laryngeal cancer it remains one of the deadly diseases. In this study 72 laryngeal cancer patients were studied and it was found that $86.1 \%$ of the study participants were male compared to female which was $13.9 \%$ this corresponds to the study done by Owen PyekoMenach et al on demographic and histology pattern of laryngeal squamous cell carcinoma in Kenya, which demonstrate that only $4 \%$ were female and male was $96 \%$ of all patients [12] These results obtained are largely contributed by the fact that male experience more risks behaviors like excessive alcohol consumption and cigarette smoking which lead to laryngeal cancer development compared to females who are less likely to be exposed to these risk behaviors.

The youngest patient to be included in this study was 35 years old while the oldest patient was 84 years with mean age of 58.1 years. $56.9 \%$ of the patients had age between 31 and 60 , $43.1 \%$ had age above 60 years while there was no patient with the age below 30 years. These results were consistency to the result of study done by Owen Pyeko Menach et al which shows that the mean age of the patient in his study was 63 years old. From this study it shows that, majority of laryngeal cancer are elderly people compared to other age groups in a population and this can be explained by the fact that at that age the immune system and genetic repair mechanism is poor compared to younger age where by the repair mechanisms and the immune status are effective.

According to the study done by Arsenijevic S et al. [12] to define demographic characteristic of patients with laryngeal cancer and their socioeconomic status it was observed that people of lower education level and poor socioeconomic status had increased risk of getting laryngeal cancer [12]. This correlate with our study which shows that the majority of laryngeal cancer patients in the study had primary education and below, 58.3\% with only primary education and those with no formal education were $1.4 \% \%$. This may be due to the fact that these patients have got poor knowledge on risk factors and development of laryngeal cancer and also this group with low level of education does not have a tendency to seek for right medical treatment when they start to experience early symptoms of disease.

In our study, $69.4 \%$ had history of both alcohol consumption and cigarette smoking prior to disease development, $18.1 \%$ had history of alcohol consumption alone and $12.5 \%$ cigarette smoking alone, this shows that patients who previously had both habit of cigarette smoking and alcohol consumption had higher chance of developing laryngeal cancer compared to those patients who smoke cigarette or consume alcohol alone. These results were consistent with the results of the study done by Hashibe $M$ et al. [13], in in determination of interaction between tobacco and alcohol use and the risk of head and neck cancer 


\section{Cancer therapy \& Oncology International Journal}

which shows that the effects between tobacco and alcohol use is greater than multiplicative on head and neck cancer risk [13]. Also the study done by Pelucchi C et al. [14] on alcohol and tobacco use and cancer risk for upper aero digestive tract and liver shows that the combined exposure to alcohol and tobacco has multiplicative effects on carcinogenesis of this tract [14].

From this study the majority of the patients with laryngeal cancer attended at ORCI and treated had glottic tumor with $66.7 \%$, while $33.3 \%$ had supraglottic tumor envolvement and there was no any patient who presented with subglottic tumor. These findings are consistent to some literature which label glottis as the common site of cancer of the larynx by $65 \%$, supraglottis by $35 \%$ and subglottis [15] by less than $1 \%$. Also the study done by Hassan Latifi et al. [16] in on 42 patients with squamous cell carcinoma of larynx in northwestern Iran shows that the locations involved by the tumor included as 16 cases (38\%) supraglottic, 18 cases (42.8\%) glottic, and 8 cases (19\%) were reported with unknown location [16].

ED Kitcher et al. in a retrospective study on Laryngeal Cancer at the Korle Bu Teaching Hospital Accra Ghana in 2003, shows that squamous cell carcinoma was more common histopathology by $88.7 \%$, followed by adenocarcinoma, $1.7 \%$ and other types comprises about $9.6 \%$. These findings collerate with the findings from this study which shows that squamous cell carcinoma was the common histolgy by $98.6 \%$ of all cell types compared to adenocarcinoma which was $1.4 \%$ [17].

$88.9 \%$ of patients in our study were treated with combination of chemotherapy and radiotherapy, combination of surgery and chemoradiation was delivered to $6.9 \%$ of our patients, $2 \%$ received radiotherapy alone while combination of surgery and radiotherapy was delivered to $1.4 \%$ of all patients under the study.

The majority of laryngeal cancer patients attended at ORCI from 2008 to 2011 present hoarseness of voice, 93\%. Difficult in swallowing had $47 \%$ of all patients while sore throat had $23 \%$ and neck lump alone had $17 \%$ of all patients. These results were consistent with the result of the study done by Hassan Latifi, PeymanMikaili et al. [16] on 42 with squamous cell carcinoma, the main clinical manifestations of the patients were dysphonia, dysphagia, weight loss, dyspnoea, laryngalgia ,cervical lymphadenitis, stridor, haemoptysis, coughing [16].

In this study, the treatment outcome for the patients with laryngeal cancer was highly associated with disease stage. 17 patients with stage I and II had complete disease remission and 2 patients had persistent disease with no death at this stage, for those patients who attended one follow up visit. 26 patients with stage IV disease had persistent disease, 1 patient had disease relapse while 2 patients died after completing treatment for disease. The relationship between disease stage and the treatment outcome was highly significant ( $\mathrm{p}$ - value < $0.001, \mathrm{OR}=18.342$ and $95 \%$ CI 4.192- 80.244). These results were consistent with literature which shows that the early stage disease has got good outcome compared to late stage disease $[17,18]$.

\section{Conclusion}

Most of the patients attended at ORCI are male with the age between 30 to 60 years and with low socioeconomic status. They present with late stage of the disease and squamous cell carcinoma is the most common histopathology where they receive chemo radiation treatment which offered symptomatic relief to our patients, however the proportion of our patient attaining complete disease remission following treatment in our set up is very low. This may be due to late disease presentation observed in our patients which end up receiving palliative treatment. From this study it shows that more effort from the government and all other stakeholders are required in order to prevent/reduce the occurrence of laryngeal cancer, by reducing/ stop cigarette smoking and alcohol consumption through health education, income capacity buildup and improvement of health infrastructures so as overcome late disease presentation. Also further studies to assess incidence and prevalence of laryngeal cancer with respect to socio-demographic characteristics.

\section{References}

1. Hannu S, Raitiola Juhani S, Pukander (1997) Acta Oncologica 36(1): 33-36.

2. E Jaworowiska, P Serrano-Fernandez, C Tarnowiska (2007 )clinical and epidemiological features of familial laryngeal cancer in Poland 31(4): 270-275.

3. Cancer Research Centre (2014) Laryngeal cancer statistics, England, UK.

4. International Agency for Cancer Research (2016) Countries with the Highest Incidence of larynx Cancer.

5. Global Cancer statistic Centre.

6. M P Curado, B Edwards, HR Shin (2008) Cancer incidence in five continents IARC scientific publication, Lyon. France UK cancer charity Centre.

7. Kleinsasser (1988) Tumors of the larynx and hypopharynx. Stuttgart: Georg ThiemeVerlag 1-24.

8. Lauerma S (1967) Treatment of laryngeal cancer. A study of 638 cases. Acta Otolaryngol 225.

9. Barnes L, Gnepp DR (1985) Diseases of the larynx, hypopharynx, and esophagus. In: Barnes L, ed. surgical pathology of the head and neck. New York: Marcel Dekker 141-226.

10. Yilmaz T, Hoşal S, Gedikoglu G (1998) Prognostic significance of depth of invasion in cancer of the larynx. Laryngoscope 108 (5): 764-768.

11. Arsenijevic S, Pantovic V, Gledovic Z, S tojanovicJ, Belic B (2010) Demographic characteristics of patients with Laryngeal cancer and their socioeconomic status 15 (1): 131- 135.

12. Hashibe M, Brennan P, Chuang SC (2009) Interaction between tobacco and alcohol use and the risk of head and neck cancer: pooled analysis in the International Head and Neck Cancer Epidemiology Consortium. 18(2): 541-550.

13. Pelucchi C, Gallus S, Garavello W, Bosetti C (2008) Alcohol and tobacco use, and cancer risk for upper aerodigestive tract and liver. Eur J Cancer Prev 17(4): 340-344. 
14. LWB rady, M Molls, C Nieder (2011) Decision making in radiation Oncology. Radiology.

15. Hassani Latifi, Peyman Mikaili, Kaveh Latifi, Hassan Torbati (2012) Squamous cell carcinoma of larynx in Northwest Iran. European Journal of Experimental Biology 2 (1): 242-246.

16. ED Kitcher, J Yarney, RK Gyasi, C Cheyuo (2006) Laryngeal Cancer at the Korle Bu Teaching Hospital Accra Ghana. Ghana Med J 40(2): 45-49.
17. Owen Pyeko Menach (2012) Demography and Histologic Pattern of Laryngeal Squamous Cell Carcinoma in Kenya. International Journal of Otolaryngology

18. Vincent T, Devita (2001) Cancer Principles and Practice of Oncology 6th edition. Samuel Hellman, Steven A Rosenberg By Lippincott, Philadelphia, USA.

\section{Your next submission with Juniper Publishers} will reach you the below assets

- Quality Editorial service

- Swift Peer Review

- Reprints availability

- E-prints Service

- Manuscript Podcast for convenient understanding

- Global attainment for your research

- Manuscript accessibility in different formats

( Pdf, E-pub, Full Text, Audio)

- Unceasing customer service

Track the below URL for one-step submission https://juniperpublishers.com/online-submission.php 